\title{
Attention to negative information and PTSSs during the COVID-19: A moderated mediational model
}

\author{
Yingying $\mathrm{Ye}^{1} \cdot \mathrm{Xima} \mathrm{Yang}^{1} \cdot \mathrm{Xiao}^{\mathrm{Zhou}}{ }^{1}$
}

Accepted: 3 February 2022

(c) The Author(s), under exclusive licence to Springer Science+Business Media, LLC, part of Springer Nature 2022

\begin{abstract}
Post-traumatic stress symptoms (PTSSs) have been a common negative psychological response during the COVID-19 pandemic. Previous theories emphasized the unique effects of cognitive and family factors on PTSSs and overlooked their combined role, which suggested that the mechanisms underlying PTSSs were not fully understood. To fill this gap, this study aimed to examine the associations between attention to negative information, blaming others, parent-child relationship and PTSSs, as well as the combined role of these factors on PTSSs. During the COVID-19 pandemic, 1153 college students completed self-report questionnaires. Results indicated that attention to negative information increased PTSSs, both directly and via blaming others. Moreover, parent-child relationship buffered both the exacerbating effect of attention to negative information on blaming others and the effect of blaming others on worsening PTSSs. The current study integrates existing theories, expands the field of trauma research through considering the effect of cognitive and family factors on PTSSs, and provides theoretical support for interventions to relieve PTSSs.
\end{abstract}

Keywords COVID-19 · Attention to negative information · PTSSs · Blaming others · Parent-child relationship

The outbreak of the coronavirus disease 2019 (COVID19) pandemic increased the risk of death and placed people under significant psychological pressure worldwide (Cao et al., 2020; Mahmoudabadi, 2021; Xiao, 2020). For instance, studies found that COVID-19 caused psychological problems such as anxiety, depression, and post-traumatic stress symptoms (PTSSs; Choi et al., 2020; Li et al., 2021; Peng et al., 2020), and even led to an increase in suicidal behavior (De Berardis et al., 2018). This phenomenon needs to be investigated from psychological and pathophysiological perspectives, which should inform prevention, assessment and interventions (De Berardis et al., 2018; Orsolini et al., 2020). PTSSs are common psychological responses after sudden disaster events such as the COVID-19 pandemic (Carmassi et al., 2020), and have received major research attention (Liu et al., 2020; Peng et al., 2020). Hence, it is necessary to explore the mechanisms underlying PTSSs, so as to provide guidance for clinical intervention.

Xiao Zhou

psyzx@zju.edu.cn

1 Department of Psychology and Behavioral Sciences, Zhejiang University, No. 148 Tianmushan Street, Hangzhou 310028, China
Recent studies on PTSSs during the COVID-19 pandemic have focused on assessing underlying mechanisms from various perspectives (Mahmoudi et al., 2021; Velotti et al., 2021). When the COVID-19 pandemic is examined in the context of the cognitive model of post-traumatic stress disorder (PTSD; Ehlers \& Clark, 2000), attention to negative information may be an important risk factor of PTSSs. The model posits that threat stimulus perceived by an individual may lead to attention bias, which can help the individual avoid the perceived threat and relieve distress in the short term. However, this may also impede an individual's cognitive changes and maintain PTSSs (Ehlers \& Clark, 2000). This theory also suggests that negative attention bias (e.g., attention to negative information) may be an important factor that triggers PTSSs. Attention bias towards negative information (e.g., news or rumors about COVID-19) increase individuals' tendency to readily pay attention to threatening stimuli or negative information, and make it difficult to pull away from threatening stimuli (Bar-Haim et al., 2007). This may cause hypervigilance (Vythilingam et al., 2007; Naim et al., 2015), which may in turn lead to the emergence of PTSSs. Empirical studies found that selective attention to threat stimuli was central to the development of PTSSs (Devineni et al., 2004) and aggravated their severity (Schafer 
et al., 2018). On the basis of this, we propose hypothesis 1 : negative attentional bias positively predicts PTSSs.

Furthermore, the cognitive model of PTSD (Ehlers \& Clark, 2000) emphasizes that attention to negative information may also affect PTSSs through cognitive processing, such as blaming others. Blaming others refers to an attribution style in which an individual believes that the responsibility for events or outcomes should be placed on others (Garnefski et al., 2001). Such individuals pay too much attention to the negative and external aspects of an event (Bardeen \& Orcutt, 2011), externalize responsibility, blame others to maintain their dignity and sense of meaning (Tennen \& Affleck, 1990), and avoid threats (Markowitz et al., 2021). An integrative view of the other-blame model proposed by Tennen and Affleck (1990) suggests that blaming others for one's misfortune may damage emotional health, thereby leading to individual avoidance and negative cognition and emotions, and eventually increasing PTSSs. On the basis of these studies, we propose hypothesis 2: attention to negative information can increase the emergence of PTSSs via blaming others.

However, psychological processes may differ given disparate supportive environments. Strategies to prevent the spread of COVID-19, such as home isolation and social distancing (Cao et al., 2020), changed people's social support structures (Uzun et al., 2021) As a result, the parent-child relationship was an important source of social support during this period. The multi-level family system theory proposed by Cox and Paley (1997) indicates that the parentchild relationship is an important component of the family system that could interact with children's psychological characteristics to influence their development. However, few studies have examined the parent-child relationship during the COVID-19 outbreak. Therefore, we focus on the parentchild relationship to explore role in the process of PTSSs and fill in the gap left by previous studies.

Adolescents with disparate parent-child relationships may also show heterogeneity in their psychological processes. Attachment theory suggests that individuals with good parent-child relationships may be more likely to develop secure attachment (Bowlby, 1969, 1973). These individuals find it easy to build close relationships with others (Johnson, 2019), although they may still have strong negative attention bias when confronted with threatening events. However, they may attribute the threat to the external environment rather than blaming someone else. Even if such individuals adopt blaming others as a strategy to cope with a traumatic event, a safe environment will help them actively perceive and explore more adaptive emotional cognitive strategies (Johnson, 2019), which may alleviate the severity of PTSSs. In contrast, individuals with a poor parent-child relationship are prone to developing unsafe attachment. Once an individual's attention is focused on trauma-related cues, they are more likely to perceive threats and take the initiative to explore the causes of events (Weiner, 1985; Wong \& Weiner, 1981). Because it is difficult for these people to build intimate relationships, they perceive others as threatening and find it easy to blame them. Furthermore, when individuals blame others, they may become alienated from them. This can make it difficult to receive support and recognition from others, which may in turn prompt them to use less effective strategies (Tennen \& Affleck, 1990) and increase the risk for PTSSs. On the basis of these findings, we propose hypothesis 3: the parent-child relationship may buffer the paths from attention to negative information to blaming others, and from blaming others to PTSSs.

As demonstrated in the above review, previous theories and studies have emphasized the important roles of attention to negative information, blaming others, and parent-child relationships in PTSSs. However, most of the studies ignored the combined effect of these factors, which could mean that the mechanisms underlying PTSSs are not adequately understood. Moreover, the prevalence of mental health problems among college students continued to increase even as the COVID-19 pandemic came under control (Li et al., 2021). Students urgently need effective, targeted guidance and intervention to alleviate PTSS symptoms. However, so far the combined impact of these three factors on PTSSs has not been examined in an integrated theoretical framework.

To fill this gap, the current study aimed to assess the relations between attention to negative information, blaming others, parent-child relationships, and PTSSs among college students during the COVID-19 outbreak. We drew from previous theories and studies to propose a mediated moderation model for these factors; to our knowledge this is the first time this has been done. We hypothesize that attention to negative information increases PTSSs via blaming others, and that the parent-child relationship may exert a moderating effect on this indirect path. This model is shown in Fig. 1. This model may help researchers and clinical practitioners consider the psychological mechanisms of alleviating PTSSs in college students from both cognitive and family perspectives, and provide evidence and guidance for clinical interventions.

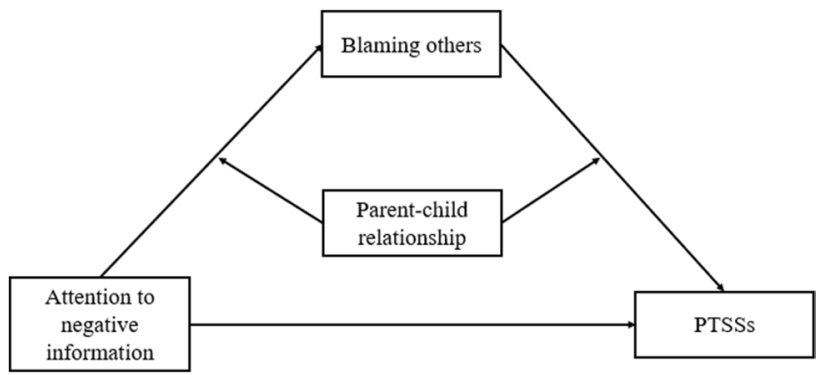

Fig. 1 Hypothesized conceptual moderated mediation effect model 


\section{Methods}

\section{Participants and Procedure}

This study recruited college students from across China to investigate the impact of COVID-19 on their mental health. Data were collected via the Internet using an online questionnaire survey platform in May 2020. No compensation was offered for participation. Informed consent was obtained from each participant before starting the survey, which emphasized that their personal information would be protected. This study was approved by the research ethics committee of Zhejiang University.

Data were collected from 1153 Chinese college students; all participants were included in our study. Participants' mean age was 20.2 years (standard deviation $[S D]=1.38$ ). Of these, 602 (52.2\%) were female, $665(57.7 \%)$ were from rural areas, $313(27.1 \%)$ reported they were in love, and 475 $(41.2 \%)$ were the only child in their family.

\section{Instruments}

Exposure to the Pandemic We used the Epidemic Experience Scale developed by Zhen and Zhou (2020). This scale consists of 10 items that are scored 0 (no) or 1 (yes). The Cronbach's $\alpha$ for the current study was 0.68 .

Attention to Negative Information The Attention to Positive and Negative Information Scale was developed by Noguchi et al. (2006) and revised by Lv et al. (2016). This subscale has 11 items and is scored on a 5-point Likert-type scale from 1 (completely disagree) to 5 (completely agree). In this study, the Cronbach's $\alpha$ for the subscale was 0.90 .

Parent-Child Relationships The Chinese version of the Parent-Adolescent Relationship Questionnaire (Wang \& Zhang, 2007) was used in this study. This tool includes 10 items that are rated on a 5-point Likert-type scale from 1 (very inconsistent) to 5 (very consistent). The Cronbach's $\alpha$ for this questionnaire was 0.75 in the current study.

Blaming Others This was measured using the blaming others subscale from the Cognitive Emotion Regulation Questionnaire, which was developed by Garnefski et al. (2001) and revised by Zhu et al. (2007). The blaming others subscale includes 4 items rated on a 5-point Likert-type scale from 0 (almost never) to 4 (almost always). This subscale had solid internal consistency (Cronbach's $\alpha=0.94$ ).

PTSSs The self-report PTSD Checklist (PCL-5) was developed by Weathers et al. (2013) and revised by Zhou et al.
(2017). The PCL-5 consists of 20 items and is scored on a 5-point Likert-type scale from 0 (not at all/only once) to 4 (almost every week). A higher score indicates greater PTSSs. In this study, the Cronbach's $\alpha$ for the PCL-5 was 0.96.

\section{Data Analysis}

This survey was conducted using an online questionnaire packet. All questions were mandatory, meaning there were no missing data. SPSS version 26.0 was used for the descriptive and correlation analyses, and the Process macro in SPSS 26.0 was used to estimate the moderated mediation model (Hayes, 2017). The bootstrap method was used for the parameter estimation. The estimated sample size was 5000, and the $95 \%$ confidence interval $(\mathrm{CI})$ without 0 indicated that the parameters were significant. Attention to negative information, the parent-child relationship, blaming others, and PTSSs were standardized before analysis. Two regression analyses were conducted to examine our hypotheses. In the first regression analysis, Model 4 (Hayes, 2017) was used to test whether the relation between attention to negative information and PTSSs was mediated by blaming others. In the second regression analysis, Model 58 (Hayes, 2017) was used to examine the moderated mediation effect and clarify whether the parent-child relationship moderated the indirect effect of attention to negative information on PTSSs. If the moderated mediation effect was significant, a further test was performed where simple slope analysis was used to divide the parent-child relationship into high and low groups (high parent-child relationship group $=M+1 S D$, low parent-child relationship group $=M-1 S D$; e.g., Aiken \& West, 1991).

\section{Results}

\section{Descriptive Statistics and Correlations between Variables}

The mean $[M]$ and standard deviation $[S D]$ for each variable are presented in Table 1. Correlation analysis showed that pandemic exposure was positively correlated with both attention to negative information and PTSSs. Attention to negative information, blaming others, and PTSSs were all significantly positively correlated with each other. However, the parent-child relationship was negatively correlated with attention to negative information, blaming others, and PTSSs.

\section{Moderated Mediation Effect Analysis}

In the mediating effect test, we controlled for pandemic exposure as a covariable. The results showed that attention 
Table 1 Correlations between the main variables

\begin{tabular}{llllll}
\hline Variable & $M(S D)$ & 1 & 2 & 3 & 4 \\
\hline 1. Exposure to the pandemic & $12.43(1.68)$ & 1 & & & \\
2. Attention to negative information & $29.72(7.98)$ & $0.09^{* * *}$ & 1 & & \\
3. Blaming others & $6.87(3.38)$ & 0.05 & $0.39^{* * *}$ & 1 & \\
4. Parent-child relationship & $34.15(5.29)$ & 0.01 & $-0.25^{* * *}$ & $-0.25^{* * *}$ & 1 \\
5. PTSSs & $24.73(13.34)$ & $0.07^{* *}$ & $0.69^{* * *}$ & $0.46^{* * *}$ & $-0.31^{* * * *}$ \\
\hline
\end{tabular}

${ }^{*} p<0.05,{ }^{* *} p<0.01,{ }^{* * *} p<0.001$
Table 2 Moderated mediation model test

\begin{tabular}{|c|c|c|c|c|c|}
\hline \multicolumn{2}{|l|}{ Regression model } & \multicolumn{2}{|c|}{$\begin{array}{l}\text { Overall fitting } \\
\text { index }\end{array}$} & \multicolumn{2}{|c|}{$\begin{array}{l}\text { Regression } \\
\text { coefficient and } \\
\text { significance }\end{array}$} \\
\hline Outcome variable & Predictor variable & $\overline{R^{2}}$ & $F$ & $\bar{\beta}$ & $t$ \\
\hline \multirow[t]{4}{*}{ Blaming others } & Exposure to the pandemic & 0.43 & $64.03^{* * *}$ & 0.02 & 0.58 \\
\hline & Attention to negative information & & & 0.34 & $12.46^{* * *}$ \\
\hline & Parent-child relationship & & & -0.18 & $-6.54^{* * *}$ \\
\hline & $\begin{array}{l}\text { Parent-child relationship } \times \text { Attention to } \\
\text { negative information }\end{array}$ & & & -0.07 & $-3.00^{* *}$ \\
\hline \multirow[t]{5}{*}{ PTSSs } & Exposure to the pandemic & 0.73 & $260.49^{* * *}$ & 0.004 & 0.24 \\
\hline & Attention to negative information & & & 0.58 & $26.13^{* * *}$ \\
\hline & Parent-child relationship & & & -0.13 & $-5.96^{* * *}$ \\
\hline & Blaming others & & & 0.19 & $8.18^{* * *}$ \\
\hline & Parent-child relationship $\times$ Blaming others & & & -0.07 & $-2.89^{* *}$ \\
\hline
\end{tabular}

${ }^{*} p<0.05,{ }^{* *} p<0.01,{ }^{* * *} p<0.001$ to negative information positively and significantly predicted PTSSs ( $\beta=0.58, t=26.13$; 95\% CI: $0.54,0.63$ ), indicating that attention to negative information had a direct effect on PTSSs. Additionally, attention to negative information significantly and positively predicted blaming others ( $\beta=0.34, t=12.46$; 95\% CI: $0.29,0.40)$, and blaming others significantly and positively predicted PTSSs in the mediating model $(\beta=0.19, t=8.18 ; 95 \% \mathrm{CI}: 0.14$, $0.23)$. The $95 \% \mathrm{CI}$ of the above mediating effect did not contain 0 , indicating that attention to negative information predicted PTSSs indirectly through blaming others, and blaming others played a significant mediating role in the model. Table 2 and Fig. 2 illustrate the results of these tests.

The parent-child relationship was associated with less blaming others and fewer PTSSs $(\beta=-0.18, t=-6.54$, 95\%CI: $-0.24,-0.13 ; \beta=-0.13, t=-5.96,95 \%$ CI: -0.17 , $-0.09)$. Moreover, the interaction term of the parent-child relationship and attention to negative information had a significant negative predictive effect on blaming others ( $\beta=-0.07, t=-3.00 ; 95 \% \mathrm{CI}:-0.12,-0.03)$, suggesting that the parent-child relationship moderated the predictive effect of attention to negative information on blaming others. As shown in Fig. 3, further simple slope tests showed that attention to negative information in both the high and low parent-child relationship groups had a significant and positive predictive effect on blaming others (simple slope $=0.27$, $t=7.47, p<0.001 ;$ simple slope $=0.42, t=11.17, p<0.001$ ). However, the predictive effect between the two differed. The positive predictive effect of attention to negative information on blaming others decreased as the parent-child relationship increased, suggesting that the parent-child relationship buffered the effect of attention to negative information on blaming others.

The interaction term of the parent-child relationship and blaming others had a significant negative predictive effect on PTSSs $(\beta=-0.07, t=-2.89,95 \%$ CI: $-0.11,-0.02)$. This indicated that the parent-child relationship moderated

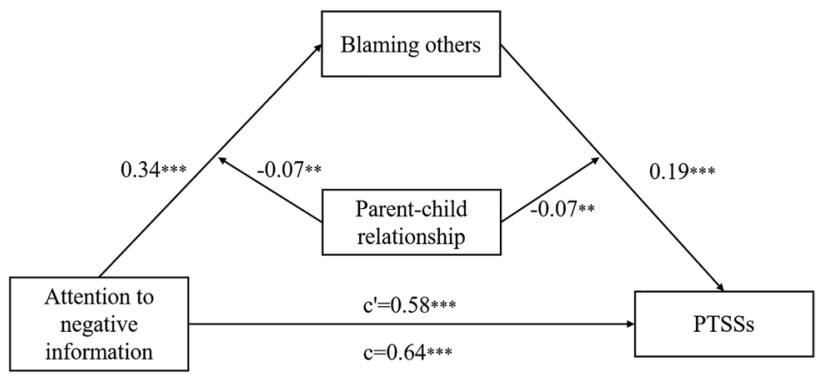

Fig. 2 Moderated mediation model 


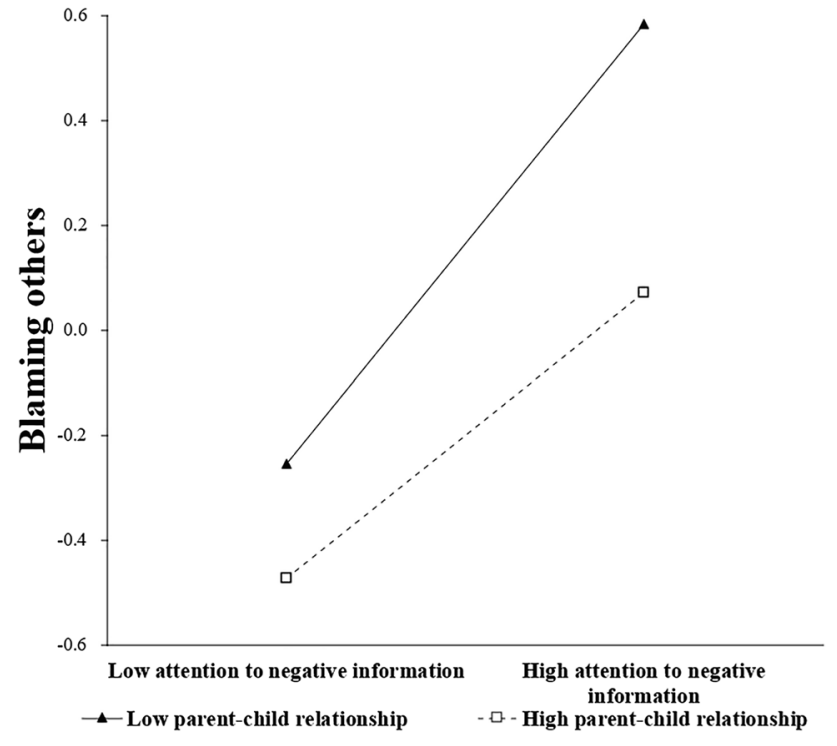

Fig. 3 The moderating role of the parent-child relationship on the association between attention to negative information and blaming others

the effect of blaming others on PTSSs. As shown in Fig. 4, further simple slope tests indicated that the positive effect of blaming others on PTSSs tended to weaken when individuals perceived a more positive parent-child relationship (simple slope $=0.11, t=3.35, p<0.001$; simple slope $=0.25, t=8.79, p<0.001)$. Therefore, the parentchild relationship buffered the effect of blaming others on PTSSs.

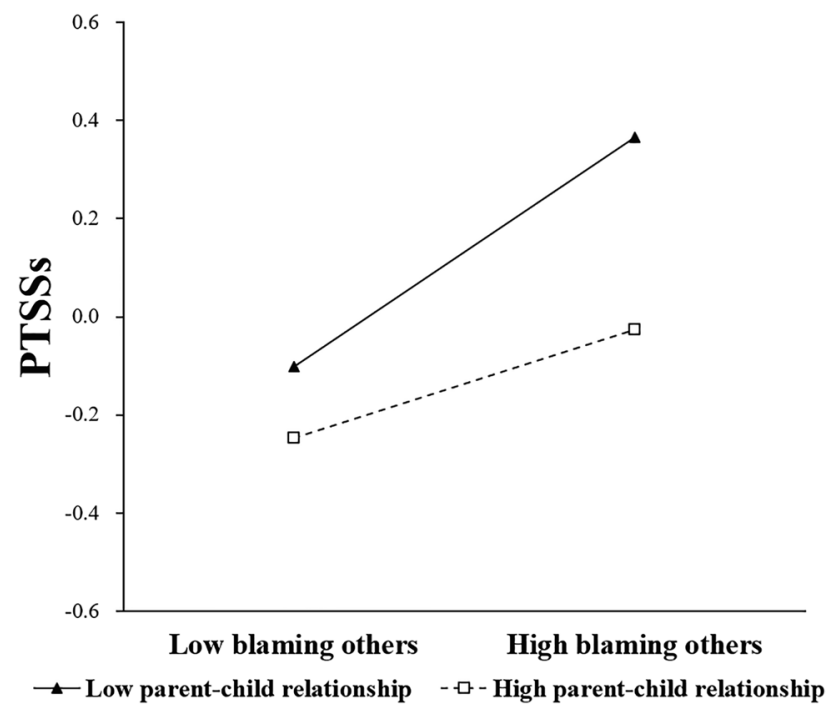

Fig. 4 The moderating role of the parent-child relationship on the association between blaming others and PTSSs

\section{Discussion}

To our knowledge, our findings are the first demonstration that individual cognitive factors (e.g., attention to negative information and blaming others) and family factors (e.g., parent-child relationships) may play a combined role in triggering PTSSs among college students during the COVID-19 pandemic, supporting the rationality of integrated theory (Ehlers \& Clark, 2000; Tennen \& Affleck, 1990). Blaming others was an important underlying cognitive mechanism whereby attention to negative information triggered PTSSs, suggesting a cognitive process in the occurrence of PTSSs. However, this process may be buffered by the parent-child relationship, which highlights the importance of family interpersonal relationships in protecting mental health.

Consistent with previous studies (e.g., Devineni et al., 2004; Schafer et al., 2018), this study found that attention to negative information had a significant and positive predictive effect on PTSSs, lending support to the cognitive model of PTSD (Ehlers \& Clark, 2000) as well as our hypothesis 1. This may be because people stayed at home during the pandemic and were exposed to a large amount of COVID-19-related negative information and rumors via the Internet. This led to attention bias and meant individuals tended to pay attention to COVID19-related threatening stimuli, which may have caused hypervigilance (Vythilingam et al., 2007; Naim et al., 2015) and negative emotions, and then resulted in PTSSs.

\section{The Mediating Role of Blaming Others}

Furthermore, attention to negative information exacerbated PTSSs via blaming others, which supported hypothesis 2 . No previous studies had demonstrated this finding directly, making ours the first to propose an integrated theory (Tennen \& Affleck, 1990; Ehlers \& Clark, 2000) that helps both in understanding the mechanisms underlying PTSSs and extends extant theories on PTSSs. To be specific, individuals with strong negative attentional bias may pay limited attention to COVID-19-related positive information and be reluctant to explore the nature of this pandemic; therefore, they may be more likely to attribute the spread of COVID-19 to others (e.g., confirmed or infected cases) and blame others. This can challenge people's worldview and affect their beliefs (e.g., "the world is wonderful" and "others are reliable"; Tennen \& Affleck, 1990), and destroy their self-satisfaction illusions, which could easily induce PTSSs.

\section{The Moderating Role of Parent-Child Relationship}

In this study, the parent-child relationship negatively predicted both blaming others and PTSSs, which supported the multi-level family system theory (Cox \& Paley, 1997). This showed that a positive parent-child relationship may 
correct individuals' negative cognition and protect their mental health, which is a basic and important family relationship, and reflects the closeness of emotional intimacy. Positive parent-child relationships allow individuals to handle COVID-19-related negative experiences and emotions and offer individuals alternative cognitive views to reframe their understanding of the pandemic. In turn, this may correct individuals' negative cognition and protect them from PTSSs.

The moderating effect analysis in this study showed that the parent-child relationship played a protective role in the effect of attention to negative information on PTSSs through blaming others, supporting hypothesis 3 . The result fills in the gaps in previous studies by providing the first evidence for the buffering effect of the parent-child relationship on the path to induce PTSSs, thus expanding the research boundaries of the trauma and family field. Individuals with a positive parent-child relationship feel more secure and stable in relationships. Even if their attention tended to focus on pandemic-related negative news (e.g., the increasing number of COVID-19 confirmed cases and deaths), they may have shared and discussed this negative news with their parents, who were their main source of social support in this period. This may have meant they were willing to actively get along with others and establish good connections (Johnson, 2019), instead of attributing responsibility for the COVID-19 outbreak to others. Even if they blamed others, the supportive environment provided by their parents may have allowed these individuals to actively explore effective coping strategies to better cope with threat events (e.g., lifestyle changes caused by COVID-19). In turn, this may have helped them maintain emotional stability (Johnson, 2019) and prevent the occurrence of PTSSs (e.g., avoidance and negative emotions).

In contrast, individuals with a poor parent-child relationship may have found it difficult to gain a sense of safety and trust. Once these individuals increased their negative attention bias toward the threat information (e.g., home isolation and delayed school opening), they may have realized that the COVID-19 pandemic led to serious socioeconomic and personal consequences. This may have led them to actively seek explanations of possible causes for the event and its outcomes (Weiner, 1985; Wong \& Weiner, 1981) to avoid their own responsibility. In turn, they may have tended to blame those who spread COVID-19, and perceived these people as a threat to society. They may even have developed anger and irritability toward these people, thereby increasing their PTSSs.

\section{Limitations}

This study provides an integrated framework to understand potential causes of PTSSs during COVID-19. However, there are still several limitations. First, our study only investigates one single type of traumatic event (i.e., COVID-19 pandemic). In the future, these findings need to be validated with different types of traumatic events to increase the generalizability of the model. Second, the cross-sectional design means conclusions about how PTSSs arises should be interpreted with caution. In the future, longitudinal studies could be conducted to examine the effects of cognitive and family factors on children with PTSSs more clearly. Third, selfreport questionnaires (such as measurement of attention to negative information, or blaming others) may lead to report bias, so other methods to measure negative attentional bias should be used in the future. Finally, this study did not differentiate between father-child and mother-child relationships, so it was impossible to compare the effects of the two kinds of parent-child relationship on children's PTSSs; this should be explored in the future.

\section{Implications}

This study has important theoretical and practical implications. In terms of its theoretical contribution, our study combined the cognitive model of PTSD (Ehlers \& Clark, 2000), Tennen and Affleck's (1990) theory, and the multi-level family system theory (Cox \& Paley, 1997) to explain the occurrence of PTSSs. It was the first demonstration that the parent-child relationship and blaming others can be regarded as cognitive and family factors that influence the relationship between attention to negative information and PTSSs. These findings promote the convergence of the trauma and family research fields, further expand the role of family and cognitive factors in trauma, and provide a more complete perspective for follow-up research. In clinical practice, the current study indicates that enhancing the parent-child relationship and reducing attention bias to negative information and blaming others are key intervention points for alleviating PTSSs in college students. To be specific, teachers, psychological consultants, and social workers should correct college students' attention bias to negative information and help them make reasonable attributions as to the cause of the COVID-19 pandemic. However, considering the longterm effects of COVID-19, it is more necessary to improve the quality of parent-child relationships through attachmentbased psychological interventions (Kitagawa et al., 2021), which may increase individuals' perceived support and relieve their PTSSs for a longer period.

\section{Conclusion}

The findings of the current study reveal that blaming others is an important mechanism by which attention to negative information triggers PTSSs, and that the parent-child 
relationship plays a protective role against PTSSs. In light of these, this study contributes to the literature by providing an integrative framework to better explain how cognitive factors influence PTSSs, as well as how family factors play a buffering role. Practically, the current study also provides theoretical support for PTSSs interventions, such as enhancing the parent-child relationship and reducing attention bias to negative information and blaming others. Future research should include longitudinal or other methods to further examine the causal impact of cognitive and family factors on PTSSs.

Funding This study was supported by the General Project for National Social Science Fund of China (Grant No. 20BSH167).

\section{Declarations}

Conflict of Interests None.

\section{References}

Aiken, L. S., \& West, S. G. (1991). Multiple regression: Testing and interpreting interactions. SAGE Publications.

Bardeen, J. R., \& Orcutt, H. K. (2011). Attentional control as a moderator of the relationship between posttraumatic stress symptoms and attentional threat bias. Journal of Anxiety Disorders, 25, 10081018. https://doi.org/10.1016/j.janxdis.2011.06.009

Bar-Haim, Y., Lamy, D., Pergamin, L., Bakermans-Kranenburg, M. J., \& van, I. M. H. (2007). Threat-related attentional bias in anxious and nonanxious individuals: A meta-analytic study. Psychological Bulletin, 133, 1-24. https://doi.org/10.1037/0033-2909.133.1.1

Bowlby, J. (1969). Attachment and loss: Vol. 1. Attachment. Basic Books.

Bowlby, J. (1973). Attachment and loss: Vol. 2. Separation: Anxiety and anger. Basic Books.

Cao, W., Fang, Z., Hou, G., Han, M., Xu, X., Dong, J., \& Zheng, J. (2020). The psychological impact of the COVID-19 epidemic on college students in China. Psychiatry Research, 287, 112934. https://doi.org/10.1016/j.psychres.2020.112934

Carmassi, C., Foghi, C., Dell'Oste, V., Cordone, A., Bertelloni, C. A., Bui, E., \& Dell'Osso, L. (2020). PTSD symptoms in healthcare workers facing the three coronavirus outbreaks: What can we expect after the COVID-19 pandemic. Psychiatry Research, 292, 113312. https://doi.org/10.1016/j.psychres.2020.113312

Choi, E. P. H., Hui, B. P. H., \& Wan, E. Y. F. (2020). Depression and anxiety in Hong Kong during COVID-19. International Journal of Environmental Research and Public Health, 17(10), 3740. https:// doi.org/10.3390/ijerph17103740

Cox, M. J., \& Paley, B. (1997). Families as systems. Annual Review of Psychology, 48, 243-267. https://doi.org/10.1146/annurev.psych. 48.1.243

De Berardis, D., Fornaro, M., Valchera, A., Cavuto, M., Perna, G., Di Nicola, M., . . \& Tomasetti, C. (2018). Eradicating suicide at its roots: Preclinical bases and clinical evidence of the efficacy of ketamine in the treatment of suicidal behaviors. International Journal of Molecular Sciences, 19(10), 2888. https://doi.org/10. 3390/ijms 19102888.

Devineni, T., Blanchard, E. B., Hickling, E. J., \& Buckley, T. C. (2004). Effect of psychological treatment on cognitive bias in motor vehicle accident-related posttraumatic stress disorder. Journal of Anxiety Disorders, 18, 211-231. https://doi.org/10.1016/S08876185(02)00247-5

Ehlers, A., \& Clark, D. M. (2000). A cognitive model of posttraumatic stress disorder. Behaviour Research and Therapy, 38, 319-345. https://doi.org/10.1016/s0005-7967(99)00123-0

Garnefski, N., Kraaij, V., \& Spinhoven, P. (2001). Negative life events, cognitive emotion regulation and emotional problems. Personality and Individual Differences, 30, 1311-1327. https://doi.org/10. 1016/S0191-8869(00)00113-6

Hayes, A. F. (2017). Introduction to mediation, moderation, and conditional process analysis: A regression-based approach. The Guilford Press.

Johnson, S. M. (2019). Attachment theory in practice: Emotionally focused therapy (EFT) with individuals, couples, and families. The Guilford Press.

Kitagawa, M., Iwamoto, S., Umemura, T., Kudo, S., Kazui, M., Matsuura, H., \& Mesman, J. (2021). Attachment-based intervention improves Japanese parent-child relationship quality: A pilot study. Current Psychology, 1-11. https://doi.org/10.1007/ S12144-020-01297-9.

Li, Y., Zhao, J., Ma, Z., McReynolds, L. S., Lin, D., Chen, Z., Wang, T., Wang, D., Zhang, Y., Zhang, J., Fan, F., \& Liu, X. (2021). Mental health among college students during the COVID-19 pandemic in China: A 2-wave longitudinal survey. Journal of Affective Disorders, 281, 597-604. https://doi.org/10.1016/j.jad.2020.11.109

Liu, N., Zhang, F., Wei, C., Jia, Y., Shang, Z., Sun, L., Wu, L., Sun, Z., Zhou, Y., Wang, Y., \& Liu, W. (2020). Prevalence and predictors of PTSS during COVID-19 outbreak in China hardest-hit areas: Gender differences matter. Psychiatry Research, 287, 112921. https://doi.org/10.1016/j.psychres.2020.112921

Lv, Y., Guo, J., \& Zhang, Y. (2016). A revision of the attention to positive and NegativeInformation scale(APNI) in Chinese children. Chinese. Journal of Clinical Psychology, 24, 861-864. https:// doi.org/10.16128/j.cnki.1005-3611.2016.05.021

Mahmoudabadi, A. (2021). Statistical similarity of mortality and recovery ratios for Covid-19 patients based on gender and age. HighTech and Innovation Journal, 2(4), 320-327. https://doi.org/10. 28991/HIJ-2021-02-04-05

Mahmoudi, H., Saffari, M., Movahedi, M., Sanaeinasab, H., RashidiJahan, H., Pourgholami, M., Poorebrahim, A., Barshan, J., Ghiami, M., Khoshmanesh, S., Potenza, M. N., Lin, C. Y., \& Pakpour, A. H. (2021). A mediating role for mental health in associations between COVID-19-related self-stigma, PTSD, quality of life, and insomnia among patients recovered from COVID-19. Brain and Behavior, 11, e02138. https://doi.org/10.1002/brb3.2138

Markowitz, D. M., Shoots-Reinhard, B., Peters, E., Silverstein, M. C., Goodwin, R., \& Bjalkebring, P. (2021). Dehumanization during the COVID-19 pandemic. Frontiers in Psychology, 12, 634543. https://doi.org/10.3389/fpsyg.2021.634543

Naim, R., Abend, R., Wald, I., Eldar, S., Levi, O., Fruchter, E., Ginat, K., Halpern, P., Sipos, M. L., Adler, A. B., Bliese, P. D., Quartana, P. J., Pine, D. S., \& Bar-Haim, Y. (2015). Threat-related attention Bias variability and posttraumatic stress. American Journal of Psychiatry, 172, 1242-1250. https://doi.org/10.1176/appi.ajp. 2015.14121579

Noguchi, K., Gohm, C. L., \& Dalsky, D. J. (2006). Cognitive tendencies of focusing on positive and negative information. Journal of Research in Personality, 40, 891-910. https://doi.org/10.1016/j. jrp.2005.09.008

Orsolini, L., Latini, R., Pompili, M., Serafini, G., Volpe, U., Vellante, F., ... \& De Berardis, D. (2020). Understanding the Complex of Suicide in Depression: from Research to Clinics. Psychiatry Investigation, 17(3), 207-221. https://doi.org/10.30773/pi.2019.0171.

Peng, M., Mo, B., Liu, Y., Xu, M., Song, X., Liu, L., Fang, Y., Guo, T., Ye, J., Yu, Z., Deng, Q., \& Zhang, X. (2020). Prevalence, risk 
factors and clinical correlates of depression in quarantined population during the COVID-19 outbreak. Journal of Affective Disorders, 275, 119-124. https://doi.org/10.1016/j.jad.2020.06.035

Schafer, J., Zvielli, A., Hofler, M., Wittchen, H. U., \& Bernstein, A. (2018). Trauma, attentional dysregulation, and the development of posttraumatic stress: An investigation of risk pathways. Behaviour Research and Therapy, 102, 60-66. https://doi.org/10.1016/j.brat. 2018.01.004

Tennen, H., \& Affleck, G. (1990). Blaming others for threatening events. Psychological Bulletin, 108, 209-232. https://doi.org/10. 1037/0033-2909.108.2.209

Uzun, H., Karaca, N. H., \& Metin, S. (2021). Assesment of parent-child relationship in Covid-19 pandemic. Children and Youth Services Review, 120, 105748. https://doi.org/10.1016/j.childyouth.2020. 105748

Velotti, P., Civilla, C., Rogier, G., \& Beomonte Zobel, S. (2021). A fear of COVID-19 and PTSD symptoms in pathological personality: The mediating effect of dissociation and emotion dysregulation. Frontiers in Psychiatry, 12, 590021. https://doi.org/10.3389/fpsyt. 2021.590021

Vythilingam, M., Blair, K. S., McCaffrey, D., Scaramozza, M., Jones, M., Nakic, M., Mondillo, K., Hadd, K., Bonne, O., Mitchell, D. G., Pine, D. S., Charney, D. S., \& Blair, R. J. (2007). Biased emotional attention in post-traumatic stress disorder: A help as well as a hindrance? Psychological Medicine, 37, 1445-1455. https:// doi.org/10.1017/S003329170700092X

Wang, M., \& Zhang, W. (2007). A research on parent-adolescent conflict and cohesion. Journal of. Psychological Science, 30, 11961198. https://doi.org/10.16719/j.cnki.1671-6981.2007.05.040
Weathers, F. W., Litz, B. T., Keane, T. M., Palmieri, P. A., Marx, B. P., \& Schnurr, P. P. (2013). The PTSD checklist for DSM-5(PCL-5). Retrieved from the National Center for PTSD. https://www.ptsd. va.gov/.

Weiner, B. (1985). "spontaneous" causal thinking. Psychological Bulletin, 97, 74-84. https://doi.org/10.1037/0033-2909.97.1.74

Wong, P. T., \& Weiner, B. (1981). When people ask "why" questions, and the heuristics of attributional search. Journal of Personality and Social Psychology, 40, 650-663. https://doi.org/10.1037/ 0022-3514.40.4.650

Xiao, C. (2020). A novel approach of consultation on 2019 novel coronavirus (COVID-19)-related psychological and mental problems: Structured letter therapy. Psychiatry Investigation, 17, 175-176. https://doi.org/10.30773/pi.2020.0047

Zhen, R., \& Zhou, X. (2020). Predictive factors of public anxiety under the outbreak of COVID-19. Chinese Journal of Applied Psychology, 26, 99-107.

Zhou, X., Wu, X. C., \& Zhen, R. (2017). Assessing the latent structure of DSM-5 PTSD among Chinese adolescents after the Ya'an earthquake. Psychiatry Research, 254, 33-39. https://doi.org/10. 1016/j.psychres.2017.04.029

Zhu, X., Luo, F., Yao, S., Auerbach, R. P., \& Abela, J. R. Z. (2007) Reliability and validity of the cognitive emotion regulation questionnaire-chinese version. Chinese Journal of Clinical Psychology, 15, 121124+131.

Publisher's Note Springer Nature remains neutral with regard to jurisdictional claims in published maps and institutional affiliations. 